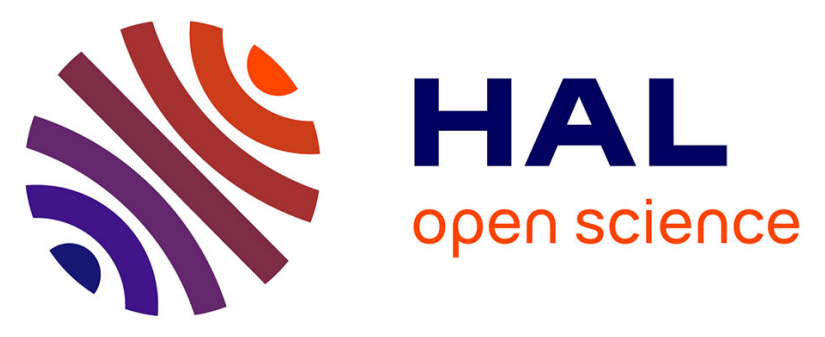

\title{
Lifestyle Intervention Enhances HDL Function among Patients with Metabolic Syndrome Only at Normal LDL-Cholesterol Plasma Levels
}

Boris Hansel, Dominique Bonnefont-Rousselot, Alexina Orsoni, Randa Bittar, Philippe Giral, Ronan Roussel, Michel Marre, Kamel Mohammedi, Eric

Bruckert, M.John Chapman, et al.

\section{To cite this version:}

Boris Hansel, Dominique Bonnefont-Rousselot, Alexina Orsoni, Randa Bittar, Philippe Giral, et al.. Lifestyle Intervention Enhances HDL Function among Patients with Metabolic Syndrome Only at Normal LDL-Cholesterol Plasma Levels. Journal of clinical lipidology, 2016, 10.1016/j.jacl.2016.05.008 . hal-01318482

\section{HAL Id: hal-01318482 https://hal.sorbonne-universite.fr/hal-01318482}

Submitted on 19 May 2016

HAL is a multi-disciplinary open access archive for the deposit and dissemination of scientific research documents, whether they are published or not. The documents may come from teaching and research institutions in France or abroad, or from public or private research centers.
L'archive ouverte pluridisciplinaire HAL, est destinée au dépôt et à la diffusion de documents scientifiques de niveau recherche, publiés ou non, émanant des établissements d'enseignement et de recherche français ou étrangers, des laboratoires publics ou privés. 


\section{LIFESTYLE INTERVENTION ENHANCES HDL FUNCTION AMONG PATIENTS WITH}

METABOLIC SYNDROME ONLY AT NORMAL LDL-CHOLESTEROL PLASMA LEVELS

Boris HANSEL $^{* a, b, c}$, Dominique BONNEFONT-ROUSSELOT ${ }^{\text {d,e,f }}$, Alexina ORSONI $^{\mathrm{e}}$, Randa BITTAR $^{\mathrm{d}, \mathrm{e}}$, Philippe GIRAL ${ }^{\mathrm{g}}$, Ronan ROUSSEL ${ }^{\mathrm{a}, \mathrm{b}, \mathrm{c}}$, Michel MARRE ${ }^{\mathrm{a}, \mathrm{b}, \mathrm{c},}$ Kamel

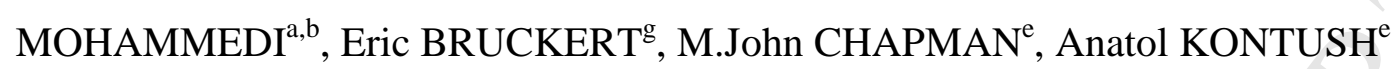

${ }^{a}$ Département d'Endocrinologie, Diabétologie et Nutrition, DHU FIRE, Hôpital Bichat, Assistance Publique-Hôpitaux de Paris, France

${ }^{\mathrm{b}}$ INSERM U1138, Centre de Recherche des Cordeliers, Paris, France

${ }^{\mathrm{c}}$ Université Paris-Diderot, Paris 7, Paris, France

${ }^{\mathrm{d}}$ Service de Biochimie Métabolique, Groupe hospitalier Pitié-Salpêtrière-Charles Foix, Assistance Publique-Hôpitaux de Paris (AP-HP), Paris, France

e INSERM UMRS 1166 ICAN, Université Pierre et Marie Curie Paris 6, Hôpital de la Pitie, Paris, France

${ }^{\mathrm{f}}$ Faculté de Pharmacie, Université Paris Descartes, Paris, France

g Service d'Endocrinologie-Métabolisme, AP-HP, Hôpital de la Pitié, Paris, France

\section{Corresponding author and person of whom requests should be addressed:}

Dr Boris Hansel, Hôpital Bichat-Claude-Bernard, Service d'Endocrinologie-Métabolisme, 46 Rue Henri Huchard, 75018 Paris, France

Tel. (33) (1) 40-25-73-01 / fax: (33) (9) 55-73-85-70,

E-mail: boris.hansel@aphp.fr

Running Title: Lifestyle intervention and HDL function

Main text word count: 4337

Number of figures and tables: 5

Abreviations: MetS, metabolic syndrome; AOX, antioxidative function; WC, waist circumference; 


\begin{abstract}
Background: Metabolic syndrome (MetS) is associated with altered lipoprotein metabolism and impairment in the functionality of small, dense HDL particles secondary to compositional alterations.

Objective: To investigate the capacity of a lifestyle program to improve the composition and antioxidative function (AOX) of small dense HDL3c in MetS.

Methods: Patients with MetS ( $\mathrm{n}=33$ ) not taking lipid-lowering drugs were recruited to follow a 12-week educational program to reduce caloric intake and to increase physical activity. HDL subfractions were preparatively isolated by isopycnic density gradient ultracentrifugation. AOX of HDL3c was assessed as its capacity to inhibit LDL oxidation induced by an azoinitiator.
\end{abstract}

Results: AOX of HDL3c was significantly improved (mean reduction in the propagation rate of LDL oxidation by HDL3c, $-6.8 \%, \mathrm{p}=0.03$ ) and systemic oxidative stress, assessed as plasma levels of 8-isoprostanes, tended to decrease in normocholesterolemic MetS patients (LDL-cholesterol (LDL-C) $<130 \mathrm{mg} / \mathrm{dl}$ ), but not in patients with elevated LDL-C levels and in the whole study population. Both in the whole study population and in the normocholesterolemic subgroup, lifestyle intervention resulted in a significant degree of normalisation of HDL3c composition, (enrichment in apolipoprotein A-I and cholesteryl esters, depletion in triglycerides), which was more pronounced at LDL-C $<130 \mathrm{mg} / \mathrm{dl}$. Conclusion: In patients with MetS, a lifestyle program improves AOX of small, dense HDL in subjects with normal LDL-C levels. Correction of HDL composition, involving partial normalisation of apoA-I content and core lipid composition, two central features of the lipid hydroperoxide-inactivating capacity of HDL, may account for this effect.

Keywords: Metabolic syndrome, High-density Lipoprotein, Antioxidative activity, Oxidative stress; Lifestyle intervention 


\section{Introduction}

Metabolic syndrome (MetS) is characterized by a constellation of cardiovascular (CV) risk factors, including atherogenic dyslipidemia, abnormal glucose tolerance, hypertension, and visceral obesity, which are intimately associated with insulin resistance and hyperinsulinemia. Lipid abnormalities associated with MetS typically include high plasma levels of triglycerides (TG) and low levels of high-density lipoprotein (HDL)-cholesterol (HDL-C). In addition, MetS is associated with altered profiles of HDL and low-density lipoprotein (LDL) subfractions characterized by increased proportions of dysfunctional small, dense, LDL and HDL particles $(1,2)$. Such alterations in lipoprotein subfraction distribution reflect metabolic perturbations associated with insulin resistance and accumulation of visceral fat, which result in enrichment of LDL and HDL particles in TG with concomitant depletion in cholesterol. Such metabolic alterations are in large part due to elevated activity of cholesteryl ester transfer protein (CETP) in the presence of elevated levels of triglyceride-rich lipoprotein acceptors (3); indeed, CETP mediates the transfer of cholesteryl esters from HDL to proatherogenic apoB-lipoproteins, with heterotransfer of TG mainly from very low-density lipoprotein to HDL (3). Such compositional modifications are accompanied by marked alterations in the biological function of the lipoproteins (4). On the one hand, the preponderance of small, dense LDL particles, which are highly susceptible to oxidative modification, increases the overall oxidizability of the circulating LDL pool. On the other hand, the capacity of HDL, and primarily of potently antioxidative, small, dense HDL3c particles to protect LDL from oxidation, is deficient among patients with MetS (5), and equally among patients with Type 2 diabetes (6) and in those with isolated low HDL-C levels (7). Importantly, under these conditions, the antioxidative activity of HDL3c was negatively correlated with elevated systemic oxidative stress, which was itself quantified as plasma 
concentrations of 8-isoprostanes and oxidized LDL (oxLDL), two biological markers known to be associated with CVD (8).

Although the results of the VA-HIT Study (9) and Helsinki Heart Study (10) have shown that increasing levels of HDL-C and lowering those of triglycerides and non-HDL-C with gemfibrozil reduces risk of CHD in patients not taking statins, recent trials of agents aimed specifically to increase HDL-C (including CETP inhibitors) have failed to confer protection against CVD in patients under statin therapy. One possible explanation for such negative results involves the lack of beneficial effects conferred by HDL-targeting drugs on the antiatherogenic function of HDL despite their positive effects on HDL-C levels. Indeed, a recent meta-regression analysis by Hourcade-Potelleret et al. suggests that the use of HDL-C as a surrogate marker of coronary events associated with abnormalities of HDL metabolism is not sufficient and that markers of HDL function may be more relevant (11). In order to reduce CV risk among patients with high levels of TG-rich lipoproteins and low plasma HDL-C levels, the European Atherosclerosis Society Consensus panel recommends lifestyle modifications as the first step in therapeutic intervention. ${ }^{11}$ Indeed, despite a relatively weak impact on HDL-C levels $(12,13)$, lifestyle modifications aimed at increasing physical activity and improving nutritional habits may reduce $\mathrm{CV}$ risk even in the absence of major alterations of traditional CV risk factors (14).

We hypothesize that beneficial effects of lifestyle modifications might be partially related to enhanced function of defective HDL particles. So far, few studies have examined the effect of lifestyle changes and/or weight loss on the anti-atherosclerotic function of HDL particles (1518). In a follow-up of our initial studies which documented impaired antioxidative and antiapoptotic activities of small, dense HDL in MetS, we assessed the effect of weight loss induced by diet and exercise on the subfraction profile of plasma HDL particles, on the antioxidative function of small, dense HDL3c and on biological markers of oxidative stress. 
Due to the heterogeneity of our population including both patients with high and desirable LDL-C plasma levels, we decided a priori to stratify analyses by LDL-C levels choosing the cutoff proposed by NCEP-ATPIII to distinguish optimal to above optimal values and borderline to very high values (19).

\section{Material and Methods}

\section{Subjects}

Thirty-three consecutive subjects ( 25 men and 8 women) were recruited at the Cardiovascular Prevention Unit of the Hopital La Pitié-Salpêtrière (Paris, France) where they participated in an educational program of 12 weeks aimed at losing weight and reducing cardiometabolic risk. All patients participating in this program were asked to follow their usual lifestyle habit and to maintain the same weight $(+/-1 \mathrm{~kg})$ during the month preceding their inclusion in the program without any changes. Patients with MetS as defined by the American Heart Association/International Diabetes Federation/International Atherosclerosis Society consensus (20) were included if they were aged between 18 and 70 years and if they took part in the two visits scheduled at our unit at an interval of 3 months+/-10 days. Exclusion criteria were BMI $\geq 40 \mathrm{~kg} / \mathrm{m}^{2}$, use of lipid-lowering agents, anti-inflammatory drugs, hormonal replacement therapy, contraceptive agents or antioxidant supplements in the 4 weeks prior the inclusion, existence of a clinical or biological (hs-CRP>10 mg/l) inflammatory state, uncontrolled hypothyroidism assessed by plasma TSH levels, renal, hepatic, gastrointestinal, pulmonary or oncological disease, and adherence to a specific diet. Patients were allowed to receive antihypertensive and antidiabetic drugs if such treatment was prescribed for at least 4 weeks preceding the recruitment and remained unchanged during the study.

Patients underwent a complete medical examination at the beginning and at the end of the intervention. Waist circumference (WC) was measured at a level midway between the lower 
rib margin and the iliac crest with the subject standing and wearing only underwear. All patients underwent blood pressure monitoring on their right or left arm at rest for $10 \mathrm{~min}$. The mean of the values excluding the first measure was used for the systolic and diastolic blood pressure.

\section{Diet and exercise intervention}

Once enrolled in the program, patients were questioned by a dietician. An individually tailored program was prescribed to each patient with priorities depending of the lipid profile at baseline. Thus, in the presence of high LDL-C levels, the primary objectives were to reduce the intake of saturated fats, trans-fats and cholesterol replacing them by unsaturated fats. When patients displayed high plasma TG levels, recommendations were focused on the reduction of alcohol intake and of calories from refined carbohydrates, while encouraging the consumption of fibre from vegetables, legumes and whole grains. All patients were encouraged to reduce the size of the portions to reduce the total daily caloric intake. In addition, patients were advised to perform $150 \mathrm{~min} /$ week of endurance exercises of moderate intensity. The program was prescribed individually to each of the participant by a sports doctor. An informed consent of all participating subjects was obtained. Each patient provided informed consent to the study, which was in accordance with French ethical standards.

\section{Blood samples}

Fasting venous blood samples were drawn on ice into tubes without any anticoagulant and into tubes containing EDTA (final concentration: $1 \mathrm{mg} / \mathrm{ml}$ ) from the ante-cubital vein of each subject after a $12 \mathrm{~h}$ fast. EDTA plasma and serum were separated by centrifugation at $4{ }^{\circ} \mathrm{C}$, mixed with sucrose (final concentration, $0.6 \%$ ) as a cryoprotectant for lipoproteins (21) and frozen at $-80^{\circ} \mathrm{C}$ under nitrogen. Total cholesterol (TC) (22) and TG (23) concentrations were determined by an automated enzymatic method (Konelab, Thermoclinical Labsystems, Cergy Pontoise, France and Biomerieux, Marcy L'Etoile, France, respectively). HDL-C was 
determined by a direct method (Konelab) (24). LDL-C was calculated using Friedewald's equation at $\mathrm{TG} \leq 340 \mathrm{mg} / \mathrm{dl}(3.9 \mathrm{mmol} / \mathrm{L})$ or directly measured at $\mathrm{TG}>340 \mathrm{mg} / \mathrm{dl}(3.9$ $\mathrm{mmol} / \mathrm{L})$ but $<700 \mathrm{mg} / \mathrm{dl}$ (8 mmol/L), using a Konelab kit (25). Blood samples were taken for analysis of complete blood count, potassium, uraemia, creatinine, uric acid, liver enzymes, fasting glucose, fasting insulin and HbA1c. The Homeostasis Model Assessment of insulin resistance (HOMA-IR) index was calculated by dividing by 22.5 the product of fasting glucose (expressed as mmol/L) and fasting insulin (expressed as mIU/L). 8-Isoprostane concentration was determined in plasma by ELISA (Cayman Chemical, Ann Arbor, MI); oxLDL was measured in plasma by ELISA (Mercodia, Sweden).

HDL subfraction profiling

The distribution of serum HDL subclasses was determined by gradient gel electrophoresis (26). After serum density adjustment to $1.019 \mathrm{~g} / \mathrm{ml}$ with potassium bromide, (VLDL+IDL) lipoproteins were first separated by ultracentrifugation of $3 \mathrm{ml}$ serum at 90,000 rpm $(560,196$ g) for $4 \mathrm{~h}$ at $10^{\circ} \mathrm{C}$ (NVT rotor Beckman XL 90). After removing the upper layer, the density of the lower layer was adjusted to $1.21 \mathrm{~g} / \mathrm{ml}$, followed by a second ultracentrifugation step at $90,000 \mathrm{rpm}(560,196 \mathrm{~g})$ for $4 \mathrm{~h}$ at $10^{\circ} \mathrm{C}$. The upper layer (density $\left.<1.21 \mathrm{~g} / \mathrm{ml}\right)$ contained LDL+HDL lipoproteins. LDL and HDL size was then determined by electrophoresis $(70 \mathrm{~V}$ for $1 \mathrm{~h}$ then $180 \mathrm{~V}$ for $24 \mathrm{~h}$ ) in a non-denaturing polyacrylamide gradient gel (Spiragel 1.525\%, Lara-Spiragel, Couternon, France) using Tris/boric acid/ $\mathrm{NaN}_{3}$ buffer ( $\mathrm{pH} 8.3$ ). Markers of known molecular weight, i.e. thyroglobulin, ferritin, catalase, lactate dehydrogenase and albumin (High Molecular Weight Calibration Kit for native electrophoresis, Amersham Biosciences), were run simultaneously with lipoproteins isolated from MetS patients and from a normolipidemic healthy donor, in order to ensure reproducibility. Gels were fixed and stained with Coomassie Brillant Blue G250/perchloric acid for 2 h, and destained with acetic acid-ethanol for at least $24 \mathrm{~h}$, and finally scanned with an optical densitometer (Sebia-Hyris2, 
Evry, France). The mean apparent diameters of the isolated lipoprotein subfractions were determined by comparison with calibration curves constructed with proteins of known Stokes diameters (High Molecular Weight Protein calibration kit; Pharmacia, Uppsala, Sweden). The calibration curve was constructed with albumin $(7.1 \mathrm{~nm})$, lactate dehydrogenase $(8.16 \mathrm{~nm})$, catalse $(9.7 \mathrm{~nm})$, ferritin $(12.2 \mathrm{~nm})$ and thyroglobulin $(17 \mathrm{~nm})$. To calculate the percentage distribution of HDL subclasses, areas under the scanned curves were integrated within the size limits, on a HYRYS densitometer (Sebia) at $570 \mathrm{~nm}$, and normalized to the total area considered as 100\%. (27) The normal ranges for HDL subfractions were: HDL2b (12.9-9.71 nm), 18-30\%; HDL2a (9.71-8.77 nm), 18-32\%; HDL3a (8.77-8.17 nm), 20-42\%; HDL3b $(8.17-7.76 \mathrm{~nm}), 7-15 \%$, and HDL3c $(7.76-7.21 \mathrm{~nm}), 4-10 \%$. The coefficients of variation for these measurements were between 4.3 and $10.4 \%$.

\section{Isolation and chemical composition of HDL subfractions}

Five major subfractions of HDL (i.e. large, light HDL2b and HDL2a and small, dense HDL3a, HDL3b, and HDL3c) were isolated by isopycnic density gradient ultracentrifugation (28). Total protein, TC, cholesteryl ester (CE), free cholesterol (FC), phospholipid (PL), and TG contents of isolated lipoprotein subfractions were determined as described elsewhere (28). Total lipoprotein mass was calculated as the sum of total protein, CE, FC, PL, and TG (29). Measurement of antioxidative activity of $H D L$

Antioxidative activity of small, dense HDL3c was assessed toward reference LDL isolated from EDTA plasma of one healthy normolipidemic control subject and used throughout the study. Before oxidation, EDTA and KBr were removed from LDL and HDL preparations by exhaustive dialysis against Dulbecco's PBS (pH 7.4) for $24 \mathrm{~h}$ at $4^{\circ} \mathrm{C}$ with 3 baths of 8 hours each. Before the dialysis, PBS was treated with Chelex 100 ion-exchange resin (BioRad, Marnes-la-Coquette, France) to remove transition metal ions in order to prevent artefactual lipid peroxidation. LDL oxidation was performed in the presence of a water-soluble azo- 
initiator 2,2-azobis-(2-amidinopropane) hydrochloride (AAPH). LDL (10 mg TC/dl) was incubated at $37^{\circ} \mathrm{C}$ in Dulbecco's PBS ( $\left.\mathrm{pH} 7.4\right)$ in the presence of 1mM AAPH; HDL3c (10 $\mathrm{mg}$ total mass/dl) were added to LDL directly before oxidation. PBS solution was treated with Chelex 100 ion exchange resin for $1 \mathrm{~h}$ to remove contaminating transition metal ions. Accumulation of conjugated dienes was measured as the increment in absorbance at $234 \mathrm{~nm}$ (30). The kinetics of diene accumulation revealed two characteristic phases, the lag and propagation phases. For each curve, the duration of each phase, average oxidation rates within each phase and amount of dienes formed at the end of the propagation phase (maximal amount of dienes) were calculated.

\section{Statistical analysis}

Means \pm SD are shown for all continuous variables. The paired Student's t-test was used to compare differences in clinical and biological parameters at the beginning versus the end of the study. Pearson's correlation coefficients were computed to assess associations between continuous variables. Since distributions of TG, hs-CRP, 8-isoprostanes and HOMA-IR levels were skewed, logarithmic transformations of these variables were performed before statistical analysis. The primary endpoint of the study was the amelioration of HDL antioxidative activity. On the basis of our earlier data on the defective antioxidative function of HDL in MetS,(5) we considered that the inclusion of 26 patients was sufficient to detect, with a $\beta=0.10$ and a $\alpha=0.05$, a significant improvement of $>15 \%$ (SD: 15 ) in the antioxidative activity of HDL, measured as the duration of the propagation phase, between the baseline and the end of the lifestyle intervention as well as a decrease of $>15 \%$ in the oxidation rate in the propagation phase. Due to incertitude of the effects of the lifestyle educational program, we increased the sample size and recruited 40 consecutive patients. Biochemical analyses were not performed in 7 patients due to blood samples hemolysis, resulting in a final sample size of 33 subjects. The analysis in the entire cohort was further completed by a subgroup analysis 
according to LDL-C levels based on the cutoff proposed by NCEP-ATPIII (19), (1) the subgroup of patients with MetS and normal (optimal/near-optimal) LDL-C ( $\leq 130 \mathrm{mg} / \mathrm{dl}$ ) and (2) the subgroup of patients with MetS and supranormal (borderline-high/ high/very high) LDL-C levels (>130 mg/dl).The difference between the two subgroups for the change in oxidative stress and antioxidative function of HDL were analyzed in univariate and multivariate analysis after adjustment for variables whose values differed at baseline $(p<0.05)$ between the two subgroups of patients (LDL-C>130 mg/dl vs LDL-C $\leq 130 \mathrm{mg} / \mathrm{dl}$ ). The STATISTICA computer program, version 6.0 (StatSoft, Maisons-Alfort, France) was used for all calculations. All statistical tests were two-sided at the 5\% significance. 


\section{Results}

Impact of the lifestyle intervention on clinical and biological characteristics

The clinical and biological characteristics of the population at baseline and the effect of the intervention are summarized in Table 1, and Figures 1. The mean weight loss was $4.5 \mathrm{~kg}$ ( $p<0.001)$ corresponding to a $4.5 \%$ reduction $(p<0.001)$ of the weight measured at baseline and to a $1.53 \mathrm{~kg} / \mathrm{m}^{2}$ reduction of BMI $(\mathrm{p}<0.001)$. A parallel decrease of $6 \mathrm{~cm}$ in WC $(-4.9 \%)$ was observed $(\mathrm{p}<0.001)$. Plasma TG $(-20.5 \%, \mathrm{p}<0.001)$ and aminotransferase (up to $-11.6 \%$, $\mathrm{p}<0.01)$ levels significantly decreased during the intervention, whereas HDL-C increased (+ $8.9 \%, \mathrm{p}<0.005)$. LDL-C, fasting blood glucose and HOMA-IR index remained unchanged. Importantly, TG $(-29.4 \%, \mathrm{p}<0.01)$ and HOMA-IR $(-34.2 \%, \mathrm{p}<0.001)$ decreased significantly in the subgroup of patients with LDL-C $\leq 130 \mathrm{mg} / \mathrm{dl}$, whereas such changes were nonsignificant among patients with LDL-C $>130 \mathrm{mg} / \mathrm{dl}(-13.0 \% ; \mathrm{p}=0.08,+19.9 \% ; \mathrm{p}=0.61$ respectively). In addition, hs-CRP tended to decrease only among patients with LDL-C $\leq 130$ $\mathrm{mg} / \mathrm{dl}(\mathrm{p}=0.10)$.

Impact of lifestyle intervention on HDL profile and function and on biomarkers of oxidative stress in the entire population

Compared with baseline, the distribution and the composition of HDL particles (estimated by gradient gel electrophoresis according to size or following fractionation by ultracentrifugation according to density) were significantly modified by the intervention (Table 2 and Table 3 ). Decrease in the ratio of HDL3c to HDL2b and increase in the CE to TG ratio in HDL3c were observed. By contrast, the apoAI content of HDL particles was unaltered. Antioxidative activity of small, dense HDL3c did not show any significant variation at the end of the study as compared to baseline (Table 4 and Figure 1C). Plasma levels of 8-isoprostanes were similarly unaltered, whereas oxLDL (expressed as the oxLDL to LDL-C ratio which takes 
into account changes in LDL-C) tended to decrease after the intervention $(-5.5 \mu \mathrm{IU} / \mathrm{mg}, \mathrm{p}=$

\subsection{6) Figure 1D).}

Impact of the intervention on HDL quality and function and on measures of oxidative stress according to baseline LDL-C levels

A post-hoc analysis revealed that in the subgroup of patients with LDL-C $\leq 130 \mathrm{mg} / \mathrm{dl}$, the proportion of large, buoyant HDL2b increased whereas that of HDL3c decreased, resulting in a decrease in the ratio of HDL3c to HDL2b (Table 2). The content of TG in HDL3c was also altered (Table 3), resulting in a significant increase in the CE/TG ratio (Table 1).

The rate of LDL oxidation in the propagation phase in the presence of HDL $3 c$ decreased significantly between baseline and the end of the study in this subgroup $(-6.8 \%, p=0.03)$, whereas the duration of the propagation phase tended to increase $(+5.3 \%, \mathrm{p}=0.07$; Table 4 and Figure 1C). Accordingly, there was a trend to a decrease in the maximal concentration of conjugated dienes in the presence of HDL3c $(-4.0 \%, \mathrm{p}=0.11)$. Plasma 8-isoprostanes also decreased significantly after the intervention in this subgroup $(-44.4 \mathrm{pM}, \mathrm{p}=0.03)$ and the reduction of oxLDL (as the ratio to LDL-C) was of a borderline significance $(-9.8 \mu \mathrm{IU} / \mathrm{mg}, \mathrm{p}$ $=0.06$; Table 4 and Figure 1D). By contrast, no change in the distribution of HDL subfractions was observed in the subgroup of patients with LDL-C>130 mg/dl (Table 2). Similarly, in this subgroup, the content of HDL3c in CE and TG as well as the CE/TG ratio remained unaltered between the beginning and the end of the intervention (Table 2 , and $\mathbf{3}$ ). The change in the chemical composition of HDL3c tended to be different between groups ( $p=0.06$ for apoA $1 / \mathrm{TW} ; \mathrm{p}=0.09$ for the ratio $\mathrm{CE}$ to $\mathrm{TG})$

In addition, among patients with LDL-C $>130 \mathrm{mg} / \mathrm{dl}$, we observed a significant increase in the maximal concentration of conjugated dienes and a concordant non-significant increment in the rate of LDL oxidation in the propagation phase in the presence of HDL3c, both consistent with a reduction of the antioxidative protection conferred by HDL3c particles (Table 4 and 
Figure 1C). A trend to an increase in plasma 8-isoprostanes $(\mathrm{p}=0.12)$ was also observed but plasma oxLDL did not change during the intervention (Table 4 and Figure 1D). Comparisons between the effects observed in the two subgroups defined by the level of LDL$\mathrm{C}$ showed that the change in the rate of LDL oxidation in the propagation phase in the presence of HDL3c was significantly lower in subjects with lower LDL-C levels $(-6.8 \% \pm$ 11.2) as compared to those with higher LDL-C $(+2.4 \% \pm 2.4 ; \mathrm{p}=0.007$; Figure 1C). The change in the maximal diene concentration also differed significantly between the subgroups, documenting a more favorable alteration of HDL function in normocholesterolemic patients $(p=0.006$; Figure 1C). In the multivariate analysis, after adjustment for systolic and diastolic blood pressure whose values differed at baseline between the two subgroups, the difference of the rate of oxidation of LDL between the subgroups remained significant $(\mathrm{p}=0.02)$, whereas the significance for the difference between the subgroups in the maximal diene concentration $(\mathrm{p}=0.08)$ and the duration of the propagation phase $(\mathrm{p}=0.10)$ was not maintained, although the results remained consistent with those obtained using univariate analysis. 


\section{Discussion}

The present investigation reveals that a three-month lifestyle intervention aimed to induce weight loss improves the antioxidative activity of small, dense HDL3c and reduces systemic oxidative stress among patients with MetS displaying optimal/near-optimal levels of LDL-C, in parallel to reductions in weight, BMI and WC. However, in the entire population of MetS patients including subjects with high LDL-C levels, the intervention failed to improve HDL function and to reduce oxidative stress despite reductions in weight, BMI and WC.

In earlier studies, we reported that patients with MetS and Type 2 diabetes featured defective antioxidative activity of HDL and elevated oxidative stress. HDL particles comprise multiple individual molecular species differing in antioxidative properties. In this study, we focused on the HDL3c subfraction, since our previous studies revealed its potent antioxidative activity (29). We hypothesized that weight loss accompanied by a decrease in WC may reverse abnormalities of HDL3c function and oxidative stress observed in MetS. The results obtained in the present longitudinal study are consistent with this hypothesis. In view of the heterogeneity of plasma LDL-C levels in our population, we further analyzed the results by separately considering patients with optimal (or near-optimal) levels of LDL-C of $\leq 130 \mathrm{mg} / \mathrm{dl}$ on the one hand, and those with suboptimal (high or borderline high) LDL-C levels of $>130$ $\mathrm{mg} / \mathrm{dl}$ on the other. Whereas HDL function improved and oxidative stress decreased in subjects with LDL-C $\leq 130 \mathrm{mg} / \mathrm{dl}$, the effects were opposite in the subgroup with LDL-C>130 $\mathrm{mg} / \mathrm{dl}$. Accordingly, differences in these parameters between the two subgroups were statistically significant.

Two hypotheses can be proposed to explain the differential effect of our lifestyle program in the two subgroups. First, patients with high LDL-C may display a greater degree of HDL dysfunctionality with a lesser potential for functional improvement as compared patients with lower levels of LDL-C. However, in our study, antioxidative activity of HDL3c 
did not differ between the two subgroups at baseline, which does not favor this hypothesis.

We cannot however exclude that other baseline characteristics might have differed between the subgroups to influence the ability of lifestyle intervention to enhance HDL function.

Second, the contrasting results observed according to baseline LDL-C levels can be due to the differences in the diet prescribed by a dietitian and followed by the patients. Indeed, in the present study, qualitative dietary counseling was based mainly on plasma lipid levels. Thus, among patients with LDL-C $\leq 130 \mathrm{mg} / \mathrm{dl}$, the need to decrease an intake of alcohol and carbohydrates and to replace refined cereals for wheat grains was emphasized, whereas fat intake was not discouraged. Thus, the diet in this subgroup was close to the Mediterranean diet. Patients with LDL-C $>130 \mathrm{mg} / \mathrm{dl}$ were more likely to be advised to reduce primarily dietary fats, saturated fats and cholesterol, a recommendation often accompanied by an increase in carbohydrate intake if the amount of unsaturated fat is not elevated (31). This notion is supported by the improvements over the study in plasma TG levels, HOMA-IR and by a trend to increased LDL-C in patients with LDL-C $\leq 130 \mathrm{mg} / \mathrm{dl}$, which are all the classical consequences of a low carbohydrate diet. These observations contrast with a non-significant decrease in TG and HOMA-IR among patients with LDL-C>130 mg/dl, consistent with an insufficient reduction in carbohydrate intake and in foods with a high glycemic index.

Compositionally, the improvement in HDL antioxidative activity can be explained by the alterations in HDL3c in patients with LDL-C $\leq 130 \mathrm{mg} / \mathrm{dl}$. Indeed, we previously showed a positive relationship between antioxidative activity of HDL3c and its content of apoA-I and $\mathrm{CE}$ (expressed as the CE/TG ratio). The reduction of carbohydrate in the diet reduces the accumulation of VLDL, thereby decreasing the transfer of TG from VLDL to HDL and the concomitant transfer of CE from HDL to VLDL by the action of the CETP. Structurally, the relationship between TG enrichment of HDL and impairment of antioxidative activity can reflect altered conformation of the central and C-terminal domains of apoA-I $(32,33)$, which 
can modify the accessibility of Met residues to lipid hydroperoxides. Moreover, replacement of CE by TG in recombinant HDL decreases the conformational stability of apoA-I (32), resulting in TG-containing particles which readily lose apoA-I.

Importantly, the subgroup of patients with LDL-C $\leq 130 \mathrm{mg} / \mathrm{dl}$ displayed a significant reduction of biomarkers of oxidative stress. This finding is consistent with the improvement of HDL antioxidative activity in this subgroup as the latter parameter is negatively correlated with biomarkers of oxidative stress (5). By contrast, the non-significant increase in biomarkers of oxidative stress in patients with LDL-C>130 mg/dl paralleled by decreased antioxidative activity of HDL3c is consistent with a possible pro-oxidant impact of the diet proposed in this population.

Data available on the effects of lifestyle modification on HDL function are sparse. An intervention of 6 months including moderate energy restriction diet and moderate intensity exercise induced a reduction in biomarkers of insulin resistance and oxidative stress (34). However, this study did not directly evaluate HDL function . Roberts et al.(16) showed an improvement in anti-inflammatory activity of HDL after a short 21-day intervention including moderate physical activity and a diet characterized by reduced fat intake and increased consumption of non-refined carbohydrates and fibers. The authors suggested that the conversion of HDL from a pro-inflammatory to anti-inflammatory particle may improve its protective effect against LDL oxidation. Neither these results, nor those in our present study, can distinguish between the relative effects on HDL of physical activity $v s$. dietary changes alone. Two studies $(15,17)$ have specifically assessed the impact of aerobic exercise training alone on HDL antioxidative properties, showing that either a single bout or a controlled 3month training program improves the ability of HDL to delay LDL oxidation among patients with Type 2 diabetes or MetS without altering HDL-C levels. Casella et al. (15) equally 
demonstrated partial normalization of HDL composition after a physical activity program similar to that observed in our study.

Both the strengths and limitations of the present study need to be acknowledged. The major strength includes direct measurements of HDL function in thoroughly selected and wellcharacterized MetS patients, whereas the main limitations involve the lack of assessment of dietary intake and physical activity and the absence of distinction between their effects. However, weight loss was achieved via prescription, which is in line with a real-life setting. In our previous cross-sectional study (5), differences in BMI and WC between MetS patients and healthy control subjects were about 5 times greater than changes induced by lifestyle intervention in our population. In addition, we failed to demonstrate a significant effect of the lifestyle program on the antioxidative function of HDL and on oxidative stress in the whole study population. However, earlier data (5) predict a reduction of 3.5\% in the rate of LDL oxidation in the propagation phase, which is close to what we have observed.

In conclusion, we report that lifestyle modifications may improve HDL antioxidative activity in MetS patients with normal LDL-C levels. As the decision to divide the subjects in two categories was a post-hoc analysis, our data need however to be regarded as hypothesisgenerating. Further studies are required to address our hypothesis that the quality of the diet impacts antioxidative functions of HDL via correction of HDL composition beyond the effect of weight loss. Taken together with the results of two recent clinical trials, LOOK-AHEAD (35) and PREDIMED (14), our data suggest that the cardioprotective properties of a Mediterranean diet, as compared to a low-fat diet among patients with diabetes and/or MetS may, in part, reflect partial normalization of defective cardioprotective HDL function. 


\section{Acknowledgments}

These studies were supported by the National Institute for Health and Medical Research (INSERM), University of Pierre and Mary Curie (UPMC), the Fondation de France, the Agence Nationale de la Recherche (ANR) and the Fondation pour la Recherche Médicale (Paris, France). We are indepted to all subjects and nursing staff involved in the study. 


\section{References}

1. Hulthe, J., L. Bokemark, J. Wikstrand, and B. Fagerberg. 2000. The metabolic syndrome, LDL particle size, and atherosclerosis: the Atherosclerosis and Insulin Resistance (AIR) study. Arteriosclerosis, thrombosis, and vascular biology 20: 2140-2147.

2. Pascot, A., I. Lemieux, D. Prud'homme, A. Tremblay, A. Nadeau, C. Couillard, J. Bergeron, B. Lamarche, and J. P. Despres. 2001. Reduced HDL particle size as an additional feature of the atherogenic dyslipidemia of abdominal obesity. Journal of lipid research $\mathbf{4 2}$ : 2007-2014.

3. Chapman, M. J., W. Le Goff, M. Guerin, and A. Kontush. 2010. Cholesteryl ester transfer protein: at the heart of the action of lipid-modulating therapy with statins, fibrates, niacin, and cholesteryl ester transfer protein inhibitors. Eur Heart J 31: 149-164.

4. Hansel, B., A. Kontush, D. Bonnefont-Rousselot, E. Bruckert, and M. J. Chapman. 2006. Alterations in lipoprotein defense against oxidative stress in metabolic syndrome. Curr Atheroscler Rep 8: 501-509.

5. Hansel, B., P. Giral, E. Nobecourt, S. Chantepie, E. Bruckert, M. J. Chapman, and A. Kontush. 2004. Metabolic syndrome is associated with elevated oxidative stress and dysfunctional dense high-density lipoprotein particles displaying impaired antioxidative activity. J Clin Endocrinol Metab 89: 4963-4971.

6. Nobecourt, E., S. Jacqueminet, B. Hansel, S. Chantepie, A. Grimaldi, M. J. Chapman, and A. Kontush. 2005. Defective antioxidative activity of small dense HDL3 particles in type 2 diabetes: relationship to elevated oxidative stress and hyperglycaemia. Diabetologia 48 : $529-538$.

7. Kontush, A., E. C. de Faria, S. Chantepie, and M. J. Chapman. 2005. A normotriglyceridemic, low HDL-cholesterol phenotype is characterised by elevated oxidative stress and HDL particles with attenuated antioxidative activity. Atherosclerosis 182: 277-285. 
8. Carmena, R., P. Duriez, and J. C. Fruchart. 2004. Atherogenic lipoprotein particles in atherosclerosis. Circulation 109: III2-7.

9. Rubins, H. B., S. J. Robins, D. Collins, C. L. Fye, J. W. Anderson, M. B. Elam, F. H. Faas, E. Linares, E. J. Schaefer, G. Schectman, T. J. Wilt, and J. Wittes. 1999. Gemfibrozil for the secondary prevention of coronary heart disease in men with low levels of high-density lipoprotein cholesterol. Veterans Affairs High-Density Lipoprotein Cholesterol Intervention Trial Study Group. N Engl J Med 341: 410-418.

10. Frick, M. H., O. Elo, K. Haapa, O. P. Heinonen, P. Heinsalmi, P. Helo, J. K. Huttunen, P. Kaitaniemi, P. Koskinen, V. Manninen, and et al. 1987. Helsinki Heart Study: primaryprevention trial with gemfibrozil in middle-aged men with dyslipidemia. Safety of treatment, changes in risk factors, and incidence of coronary heart disease. N Engl J Med 317: 12371245.

11. Hourcade-Potelleret, F., S. Laporte, V. Lehnert, P. Delmar, R. Benghozi, U. Torriani, R. Koch, and P. Mismetti. 2015. Clinical benefit from pharmacological elevation of highdensity lipoprotein cholesterol: meta-regression analysis. Heart 101: 847-853.

12. Bays, H. E., P. P. Toth, P. M. Kris-Etherton, N. Abate, L. J. Aronne, W. V. Brown, J. M. Gonzalez-Campoy, S. R. Jones, R. Kumar, R. La Forge, and V. T. Samuel. 2013. Obesity, adiposity, and dyslipidemia: a consensus statement from the National Lipid Association. $J$ Clin Lipidol 7: 304-383.

13. Chapman, M. J., H. N. Ginsberg, P. Amarenco, F. Andreotti, J. Boren, A. L. Catapano, O. S. Descamps, E. Fisher, P. T. Kovanen, J. A. Kuivenhoven, P. Lesnik, L. Masana, B. G. Nordestgaard, K. K. Ray, Z. Reiner, M. R. Taskinen, L. Tokgozoglu, A. Tybjaerg-Hansen, G. F. Watts, and P. European Atherosclerosis Society Consensus. 2011. Triglyceride-rich lipoproteins and high-density lipoprotein cholesterol in patients at high risk of cardiovascular disease: evidence and guidance for management. European heart journal 32: 1345-1361. 
14. Estruch, R., E. Ros, J. Salas-Salvado, M. I. Covas, D. Corella, F. Aros, E. GomezGracia, V. Ruiz-Gutierrez, M. Fiol, J. Lapetra, R. M. Lamuela-Raventos, L. Serra-Majem, X. Pinto, J. Basora, M. A. Munoz, J. V. Sorli, J. A. Martinez, M. A. Martinez-Gonzalez, and P. S. Investigators. 2013. Primary prevention of cardiovascular disease with a Mediterranean diet. The New England journal of medicine 368: 1279-1290.

15. Casella-Filho, A., A. C. Chagas, R. C. Maranhao, I. C. Trombetta, F. H. Cesena, V. M. Silva, J. E. Tanus-Santos, C. E. Negrao, and P. L. da Luz. 2011. Effect of Exercise Training on Plasma Levels and Functional Properties of High-Density Lipoprotein Cholesterol in the Metabolic Syndrome. Am J Cardiol 107: 1168-1172.

16. Roberts, C. K., C. Ng, S. Hama, A. J. Eliseo, and R. J. Barnard. 2006. Effect of a short-term diet and exercise intervention on inflammatory/anti-inflammatory properties of HDL in overweight/obese men with cardiovascular risk factors. J Appl Physiol (1985) 101: $1727-1732$.

17. Iborra, R. T., I. C. Ribeiro, M. Q. Neves, A. M. Charf, S. A. Lottenberg, C. E. Negrao, E. R. Nakandakare, and M. Passarelli. 2008. Aerobic exercise training improves the role of high-density lipoprotein antioxidant and reduces plasma lipid peroxidation in type 2 diabetes mellitus. Scand J Med Sci Sports 18: 742-750.

18. Wang, Y., M. Snel, J. T. Jonker, S. Hammer, H. J. Lamb, A. de Roos, A. E. Meinders, H. Pij1, J. A. Romijn, J. W. Smit, I. M. Jazet, and P. C. Rensen. 2011. Prolonged caloric restriction in obese patients with type 2 diabetes mellitus decreases plasma CETP and increases apolipoprotein AI levels without improving the cholesterol efflux properties of HDL. Diabetes Care 34: 2576-2580.

19. Mendez, J. I., W. J. Nicholson, and W. R. Taylor. 2005. SOD isoforms and signaling in blood vessels: evidence for the importance of ROS compartmentalization. Arterioscler Thromb Vasc Biol 25: 887-888. 
20. Alberti, K. G., R. H. Eckel, S. M. Grundy, P. Z. Zimmet, J. I. Cleeman, K. A. Donato,

J. C. Fruchart, W. P. James, C. M. Loria, S. C. Smith, Jr., E. International Diabetes Federation Task Force on, Prevention, L. Hational Heart, I. Blood, A. American Heart, F. World Heart, S. International Atherosclerosis, and O. International Association for the Study of. 2009. Harmonizing the metabolic syndrome: a joint interim statement of the International Diabetes Federation Task Force on Epidemiology and Prevention; National Heart, Lung, and Blood Institute; American Heart Association; World Heart Federation; International Atherosclerosis Society; and International Association for the Study of Obesity. Circulation 120: 1640-1645.

21. Rumsey, S. C., A. F. Stucchi, R. J. Nicolosi, H. N. Ginsberg, R. Ramakrishnan, and R. J. Deckelbaum. 1994. Human plasma LDL cryopreserved with sucrose maintains in vivo kinetics indistinguishable from freshly isolated human LDL in cynomolgus monkeys. $J$ Lipid Res 35: 1592-1598.

22. Allain, C. C., L. S. Poon, C. S. Chan, W. Richmond, and P. C. Fu. 1974. Enzymatic determination of total serum cholesterol. Clin Chem 20: 470-475.

23. Fossati, P., and L. Prencipe. 1982. Serum triglycerides determined colorimetrically with an enzyme that produces hydrogen peroxide. Clin Chem 28: 2077-2080.

24. Egloff, M., D. Leglise, L. Duvillard, J. Steinmetz, M. J. Boyer, A. Ruelland, R. Agher, and I. Beucler. 1999. [Multicenter evaluation on different analyzers of three methods for direct HDL-cholesterol assay]. Ann Biol Clin (Paris) 57: 561-572.

25. Bayer, P., F. Veinberg, R. Couderc, C. Cherfils, M. Cambillau, C. Cosson, S. Fradin, P. Gillery, J. Steinmetz, A. Legrand, M. Egloff, and I. Beucler. 2005. [Multicenter evaluation of four homogenous LDL-cholesterol assays]. Ann Biol Clin (Paris) 63: 27-41.

26. Blanche, P. J., E. L. Gong, T. M. Forte, and A. V. Nichols. 1981. Characterization of human high-density lipoproteins by gradient gel electrophoresis. Biochim Biophys Acta 665 : 408-419. 
27. Vekic, J., A. Zeljkovic, Z. Jelic-Ivanovic, V. Spasojevic-Kalimanovska, N. Bogavac-

Stanojevic, L. Memon, and S. Spasic. 2009. Small, dense LDL cholesterol and apolipoprotein

B: relationship with serum lipids and LDL size. Atherosclerosis 207: 496-501.

28. Chapman, M. J., S. Goldstein, D. Lagrange, and P. M. Laplaud. 1981. A density gradient ultracentrifugal procedure for the isolation of the major lipoprotein classes from human serum. J.Lipid Res. 22: 339-358.

29. Kontush, A., S. Chantepie, and M. J. Chapman. 2003. Small, dense HDL particles exert potent protection of atherogenic LDL against oxidative stress. Arterioscler Thromb Vasc Biol 23: 1881-1888.

30. Kontush, A., C. Hubner, B. Finckh, A. Kohlschutter, and U. Beisiegel. 1995. Antioxidative activity of ubiquinol-10 at physiologic concentrations in human low density lipoprotein. Biochim.Biophys.Acta 1258: 177-187.

31. Schwingshackl, L., and G. Hoffmann. 2013. Comparison of effects of long-term lowfat vs high-fat diets on blood lipid levels in overweight or obese patients: a systematic review and meta-analysis. J Acad Nutr Diet 113: 1640-1661.

32. Sparks, D. L., W. S. Davidson, S. Lund-Katz, and M. C. Phillips. 1995. Effects of the neutral lipid content of high density lipoprotein on apolipoprotein A-I structure and particle stability. J Biol Chem 270: 26910-26917.

33. Curtiss, L. K., D. J. Bonnet, and K. A. Rye. 2000. The conformation of apolipoprotein A-I in high-density lipoproteins is influenced by core lipid composition and particle size: a surface plasmon resonance study. Biochemistry 39: 5712-5721.

34. Rector, R. S., S. O. Warner, Y. Liu, P. S. Hinton, G. Y. Sun, R. H. Cox, C. S. Stump, M. H. Laughlin, K. C. Dellsperger, and T. R. Thomas. 2007. Exercise and diet induced weight loss improves measures of oxidative stress and insulin sensitivity in adults with characteristics of the metabolic syndrome. Am J Physiol Endocrinol Metab 293: E500-506. 
35. Look, A. R. G., R. R. Wing, P. Bolin, F. L. Brancati, G. A. Bray, J. M. Clark, M.

Coday, R. S. Crow, J. M. Curtis, C. M. Egan, M. A. Espeland, M. Evans, J. P. Foreyt, S.

Ghazarian, E. W. Gregg, B. Harrison, H. P. Hazuda, J. O. Hill, E. S. Horton, V. S. Hubbard, J.

M. Jakicic, R. W. Jeffery, K. C. Johnson, S. E. Kahn, A. E. Kitabchi, W. C. Knowler, C. E.

Lewis, B. J. Maschak-Carey, M. G. Montez, A. Murillo, D. M. Nathan, J. Patricio, A. Peters,

X. Pi-Sunyer, H. Pownall, D. Reboussin, J. G. Regensteiner, A. D. Rickman, D. H. Ryan, M.

Safford, T. A. Wadden, L. E. Wagenknecht, D. S. West, D. F. Williamson, and S. Z.

Yanovski. 2013. Cardiovascular effects of intensive lifestyle intervention in type 2 diabetes.

The New England journal of medicine 369: 145-154. 
Figure legends

Figure 1: Effect of the lifestyle program on anthropometric characteristics (A, n=33), plasma lipid levels (B, n=33), antioxidative function of $\operatorname{HDL} 3 \mathrm{c}(\mathrm{C}, \mathrm{n}=33)$ and oxidative stress assessed by plasma 8 -isoprostanes $(n=30)$ and by the ratio oxLDL/LDL-C $(D, n=32)$. To assess antioxidative function of HDL, LDL oxidation was measured as conjugated diene formation by absorbance increase at $234 \mathrm{~nm}$. Small, dense HDL3c subfraction was obtained by isopycnic density gradient ultracentrifugation. Reference LDL (10 mg TC/dl) isolated from one healthy, normolipidemic subject, was incubated at $37^{\circ} \mathrm{C}$ in $\mathrm{PBS}(\mathrm{pH} 7.4)$ in the presence of a water-soluble azo-initiator of oxidation AAPH $(1 \mathrm{mM})$. HDL3c $(10 \mathrm{mg}$ total mass/dl) were added to LDL directly before oxidation. $* \mathrm{p}<0.05$ for the change between baseline and the end of the intervention; *** $\mathrm{P}<0.001$ for the change between baseline and the end of the intervention; $+<0.05$ vs group LDL-C $>130 \mathrm{mg} / \mathrm{dl}$. Error bars represent one standard deviation from the mean. 


\begin{tabular}{|c|c|c|c|c|c|c|c|c|c|}
\hline & \multicolumn{2}{|c|}{ Whole population } & \multicolumn{4}{|c|}{ Population with LDL-C $\leq 130 \mathrm{mg} / \mathrm{dl}$} & \multicolumn{3}{|c|}{ Population with LDL-C >130 mg/dl } \\
\hline & Mean (SD) & Mean (SD) & & Mean (SD) & Mean (SD) & & $\operatorname{Mean}($ SD) & Mean (SD & \\
\hline & & & & & & & & $0 / 5$ & \\
\hline Gender $(\mathbf{m} / \mathbf{w})$ & \multicolumn{2}{|c|}{$25 / 8$} & & \multicolumn{2}{|c|}{$15 / 3$} & & & & \\
\hline Antihypertensive (n [\%]) & \multicolumn{2}{|c|}{$15[45 \%]$} & & \multicolumn{3}{|c|}{$9[50 \%]$} & \multicolumn{2}{|c|}{$8[53 \%]$} & \\
\hline Antidiabetic (n [\%]) & \multicolumn{2}{|c|}{$4[12 \%]$} & & \multicolumn{3}{|c|}{$3[17 \%]$} & \multicolumn{2}{|c|}{$1[7 \%]$} & \\
\hline Waist Circ.(cm) & $111(12)$ & $105(10)$ & $<0.001$ & $112(14)$ & $105(12)$ & $<0.001$ & $110(10)$ & $104(8)$ & 0.012 \\
\hline Weight (kg) & $98,3(18.5)$ & $93.8(18.03)$ & $<0.001$ & $99.8(20.3)$ & $94(20)$ & $<0.001$ & $97.0(17.3)$ & $93.7(16.5)$ & 0.019 \\
\hline TC (mg/dl) & $230(046)$ & $222(46)$ & 0.10 & $202(39) * *$ & $195(036)$ & 0.183 & $256(37)$ & $2.45(0.41)$ & 0.262 \\
\hline TG (mg/dl) & $288(147)$ & $221(141)$ & 0.005 & $302(168)$ & $196(133)$ & 0.014 & $277(130)$ & $242(147)$ & 0.172 \\
\hline LDL-C (mg/dl) & $139(38)$ & $139(36)$ & 0.93 & $107(0.21) * *$ & $114(0.21)$ & 0.089 & $165(26)$ & $160(33)$ & 0.528 \\
\hline HDL-C (mg/dl) & $40(11)$ & $43(12)$ & 0.001 & $39(12)$ & $44(14)$ & 0.044 & $41(10)$ & $43(11)$ & 0.125 \\
\hline FBG (mM) & $5.90(1.01)$ & $5.73(1.81)$ & 0.53 & $5.88(1.28)$ & $5.95(2.58)$ & 0.760 & $5.92(0.75)$ & $5.54(0.70)$ & 0.011 \\
\hline HOMA-IR & $4.76(2.93)$ & $3.97(2.44)$ & 0.52 & $4.86(2.91)$ & $4.15(2.90)$ & 0.002 & $4.69(3.02)$ & $3.81(2.03)$ & 0.123 \\
\hline
\end{tabular}




\begin{tabular}{|c|c|c|c|c|c|c|c|c|c|}
\hline ASAT (IU/l) & $32(8)$ & $28(7)$ & 0.002 & $34(9)$ & $30(8)$ & 0.075 & $30.8(6.8)$ & $27(5)$ & 0.016 \\
\hline ALAT (IU/I) & $42(22)$ & $34(13)$ & 0.017 & $43(27)$ & 34 (13) & 0.172 & 41.7 (18.2) & $33(14)$ & 0.034 \\
\hline$\gamma$ GT (IU/l) & $59(78)$ & $48(52)$ & 0.12 & $54(37)$ & $43(30)$ & 0.095 & $64(101)$ & $52(67)$ & 0.291 \\
\hline Uric acid $(\mu \mathrm{M})$ & $403(88)$ & 377 (83) & 0.11 & $413(83)$ & $382(91)$ & 0.222 & 395 (93) & 372 (79) & 0.316 \\
\hline Hs-CRP (mg/l) & $3.02(2.06)$ & $2.67(2.85)$ & 0.70 & $3.4(2.2)$ & $2.13(1.11)$ & 0.104 & $2.7(1.9)$ & $3.09(3.67)$ & 0.617 \\
\hline
\end{tabular}

Table 1: Clinical and biological characteristics of the whole population and of the subgroups according to the baseline LDL-C level. Data are presented at baseline and at the end of the intervention. Waist Circ., waist circumference; BMI, body mass index: SBP, systolic blood pressure; DBP, diastolic blood pressure; TC, total cholesterol; TG, triglycerides; FBG, fasting blood glucose; hs-CRP, high sensitive C reactive protein; HOMA-IR, Homeostasis Model Assessment of insulin resistance; ASAT, aspartate aminotransferase; ALAT, alanine aminotransferase; $\gamma$-GT, Gamma glutamyl transpeptidases. * p $<0.05$ vs. subgroup with LDL-C $\geq 130$ mg/dl, $* * p<0.01$ vs. subgroup with LDL-C $\geq 130 \mathrm{mg} / \mathrm{dl}$. Antidiabetics were metformin, sitagliptin, repaglinide and rosiglitazone. According to the exclusion criteria, none of the patients was taking lipidlowering medication. 


\begin{tabular}{|c|c|c|c|c|c|c|c|c|c|}
\hline & \multicolumn{2}{|c|}{ Whole population } & \multicolumn{4}{|c|}{ Population with LDL-C $\leq 130 \mathrm{mg} / \mathrm{dl}$} & \multicolumn{3}{|c|}{ Population with LDL-C >130 mg/dl } \\
\hline & $\begin{array}{c}\text { Baseline } \\
\text { Mean (SD) }\end{array}$ & $\begin{array}{c}\text { End } \\
\text { Mean (SD) }\end{array}$ & $\mathbf{p}$ & $\begin{array}{c}\text { Baseline } \\
\text { Mean (SD) }\end{array}$ & $\begin{array}{c}\text { End } \\
\text { Mean (SD) }\end{array}$ & $\mathbf{p}$ & $\begin{array}{c}\text { Baseline } \\
\text { Mean (SD) }\end{array}$ & $\begin{array}{c}\text { End } \\
\text { Mean (SD) }\end{array}$ & p \\
\hline HDL3c \% (Prot) & $7(3)$ & $7(3)$ & 0.16 & $7(3)$ & $6(4)$ & 0.06 & $6(3)$ & $7(3)$ & 0.84 \\
\hline HDL3c \% (TW) & $10(1)$ & $10(1)$ & 0.59 & $10(1)$ & $9(1)$ & 0.62 & $10(1)$ & $10(2)$ & 0.81 \\
\hline HDL2b \% (Prot) & $11(9)$ & $13(9)$ & 0.02 & $11(6)$ & $14(8)$ & 0.03 & $11(1)$ & $12(10)$ & 0.27 \\
\hline HDL2b \% (TW) & $11(3)$ & $12(4)$ & 0.02 & $11(3)$ & $3(5)$ & 0.07 & $11(3)$ & $12(3)$ & 0.19 \\
\hline HDL3c/HDL2b (Prot) & $0.85(0.62)$ & $0.69(0.45)$ & 0.05 & $0.84(0.70)$ & $0.61(0.39)$ & 0.10 & $0.86(0.55)$ & $0.77(0.60)$ & 0.34 \\
\hline HDL3c/HDL2b (TW) & $0.96(0.33)$ & $0.87(0.33)$ & 0.18 & $0.93(0.31$ & $0.84(0.29)$ & 0.26 & $0.98(0.36)$ & $0.91(0.37)$ & 0.44 \\
\hline HDL3c CE/TG & $2.42(1.38)$ & $3.22(1.64)$ & 0.04 & $2.05(1.31)$ & $4.50(1.96)$ & 0.02 & $2.72(1.40)$ & $2.95(1.60)$ & 0.64 \\
\hline ApoA-I 3c/TW 3c & $0.42(0.04)$ & $0.42(0.05)$ & 0.17 & $0.41(0.03)$ & $0.44(0.03)$ & 0.03 & $0.42(0.05)$ & $0.41(0.06)$ & 0.76 \\
\hline
\end{tabular}

Table 2: Proportions of HDL subfractions in plasma separated according to their size by electrophoresis and according to their density by ultracentrifugation and relative content in CE and TG and in apoA-I in HDL3c. Prot, proteins; TW, total weight; CE, cholesteryl ester; TG, triglycerides 


\begin{tabular}{llll}
\hline & Baseline & End of the & $\mathrm{p}$ \\
& & intervention \\
\hline PL (wt \%) & 20.2 & 20.3 & 0.69 \\
TP (wt \%) & 56.5 & 59.6 & 0.10 \\
TG (wt \%) & 8.5 & 5 & 0.005 \\
CE (wt \%) & 12.5 & 13 & 0.45 \\
FC (wt \%) & 2.3 & 2.1 & 0.25 \\
apoA-I (wt \%) & 41 & 44 & 0.03 \\
apoA-I/apoA-II & 5.5 & 6.0 & 0.048 \\
\hline Table 3: Chem & & & \\
\hline
\end{tabular}

Table 3: Chemical composition of HDL3c in the whole population at baseline and at the end

of the study. Wt $\%$ the $\%$ of total mass. PL, phospholipids; TP, total proteins; TG, triglycerides;

$\mathrm{CE}$, cholesteryl esters; FC, free cholesterol 


\begin{tabular}{|c|c|c|c|c|c|c|c|c|c|}
\hline & \multicolumn{3}{|c|}{ Whole population } & \multicolumn{3}{|c|}{ Population with LDL-C $\leq 130 \mathrm{mg} / \mathrm{dl}$} & \multicolumn{3}{|c|}{ Population with LDL-C >130 mg/dl } \\
\hline & $\begin{array}{c}\text { Baseline } \\
\text { Mean (SD) }\end{array}$ & $\begin{array}{c}\text { End } \\
\text { Mean (SD) }\end{array}$ & $\mathbf{p}$ & $\begin{array}{c}\text { Baseline } \\
\text { Mean (SD) }\end{array}$ & $\begin{array}{c}\text { End } \\
\text { Mean (SD) }\end{array}$ & $\mathbf{p}$ & $\begin{array}{c}\text { Baseline } \\
\text { Mean (SD) }\end{array}$ & $\begin{array}{c}\text { End } \\
\text { Mean (SD) }\end{array}$ & $\mathbf{p}$ \\
\hline Antiox. activity of HDL3c & & & & & & & & & \\
\hline Rate of prop. phase (\%) & $67(14)$ & $65(13)$ & 0.33 & $69(13)$ & $62(10)$ & 0.03 & $66(40)$ & $68(14)$ & 0.17 \\
\hline Max conc. of CD (\%) & $104(10)$ & $104(11)$ & 0.58 & $100(9)$ & $99(11)$ & 0.11 & $104(0.11)$ & $108(10)$ & 0.02 \\
\hline Dur. of the prop. phase $(\%)$ & $139(29)$ & $141(24)$ & 0.81 & $132(20)$ & $137(17)$ & 0.08 & $146(34)$ & $144(29)$ & 0.63 \\
\hline 8-Isoprostanes (pM) & $47.8(54.3)$ & $48.3(54.2)$ & 0.73 & $60.7(70.2)$ & $16.2(12.8)$ & 0.03 & $32.7(31.5)$ & $65.9(70.7)$ & 0.12 \\
\hline OxLDL/LDL-C $(\mu \mathrm{IU} / \mathrm{mg})$ & $55.4(16.8)$ & $49.9(13.4)$ & 0.06 & $63.5(19.4)$ & $53.74(11.5)$ & 0.06 & $47.3(9.3)$ & $46.2(14.3)$ & 0.61 \\
\hline
\end{tabular}

Table 4: Plasma levels of oxidative stress and antioxidative function of HDL3c (\% relative to LDL oxidized in the absence of HDL3c) and measures of oxidative stress at baseline and at the end of the intervention in the whole population and in the two subpopulations defined by the levels of LDL-C at baseline are shown. Rate of prop. phase, oxidation rate in the propagation phase. Dur. of the prop. phase; duration of the propagation phase. Max conc. of CD. Maximal concentration of conjugated dienes. Percentages are calculated relative to corresponding values measured in LDL oxidized alone (in the absence of HDL). CD, conjugated Dienes 
A

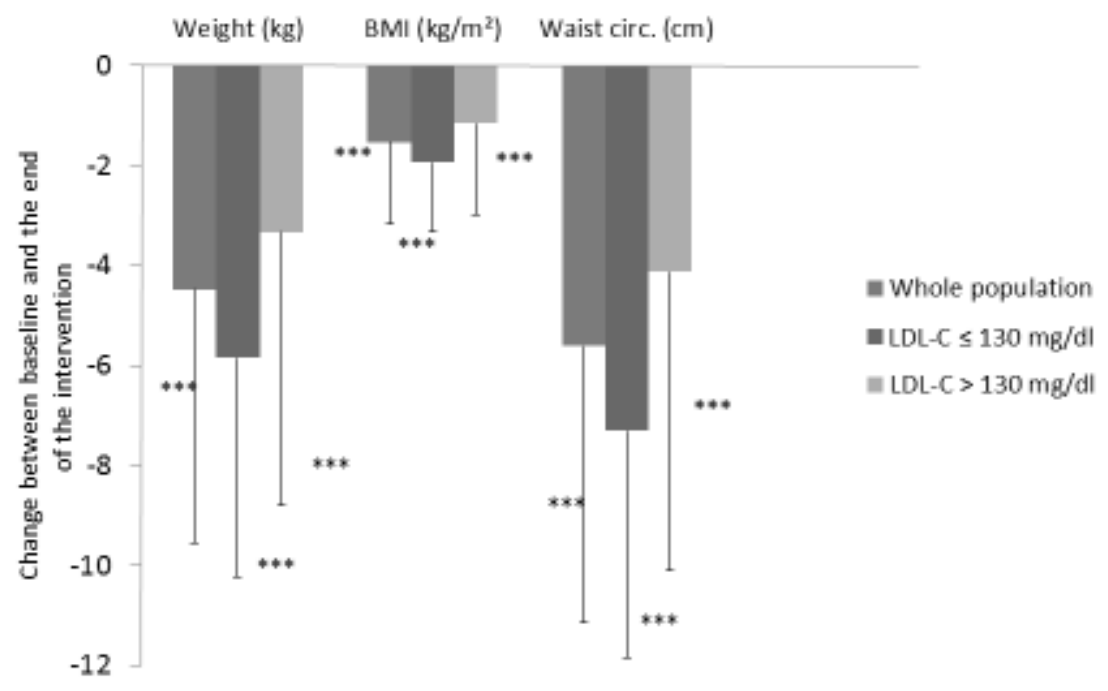

Figure 1 


\section{B}
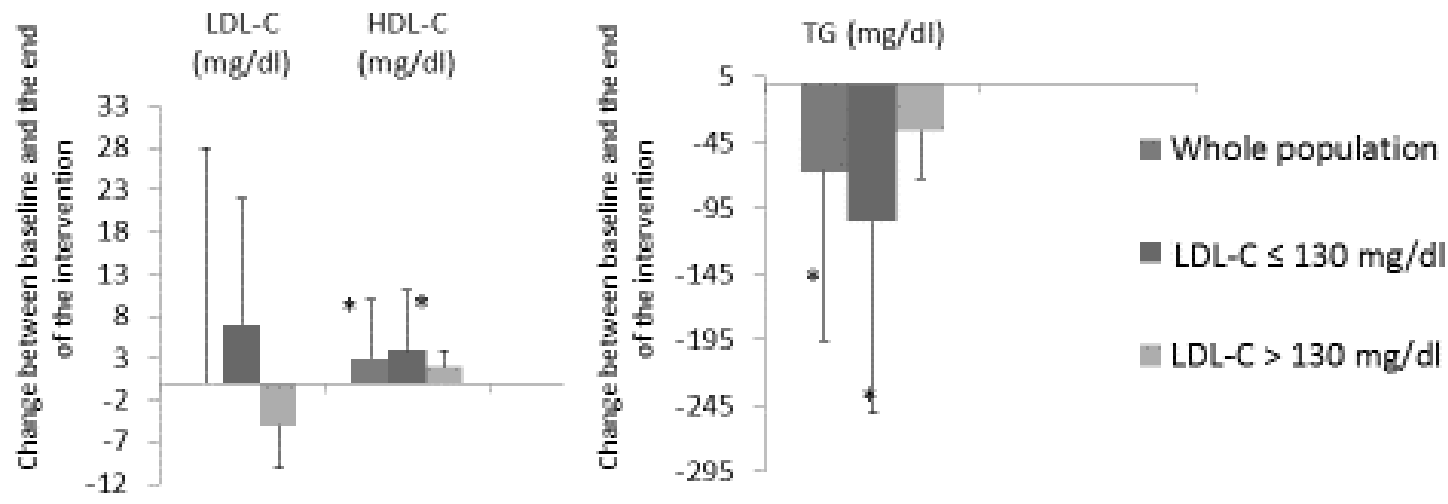


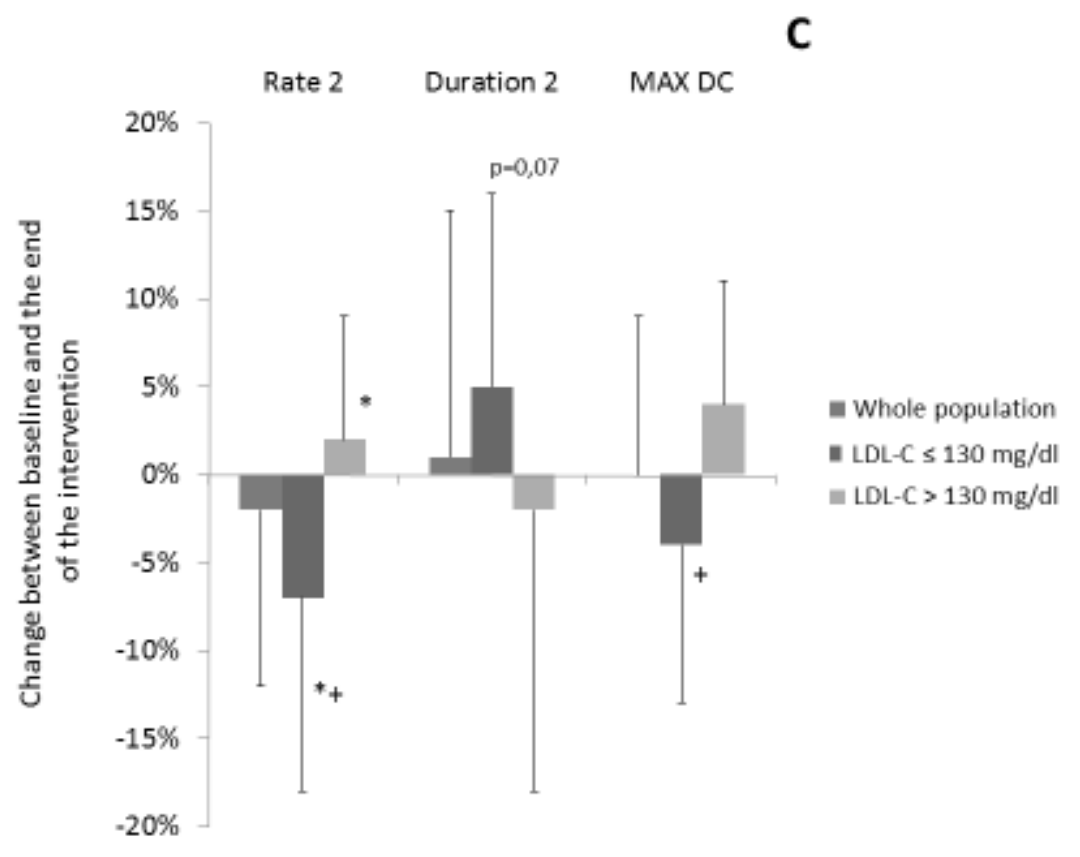

Figure 1 

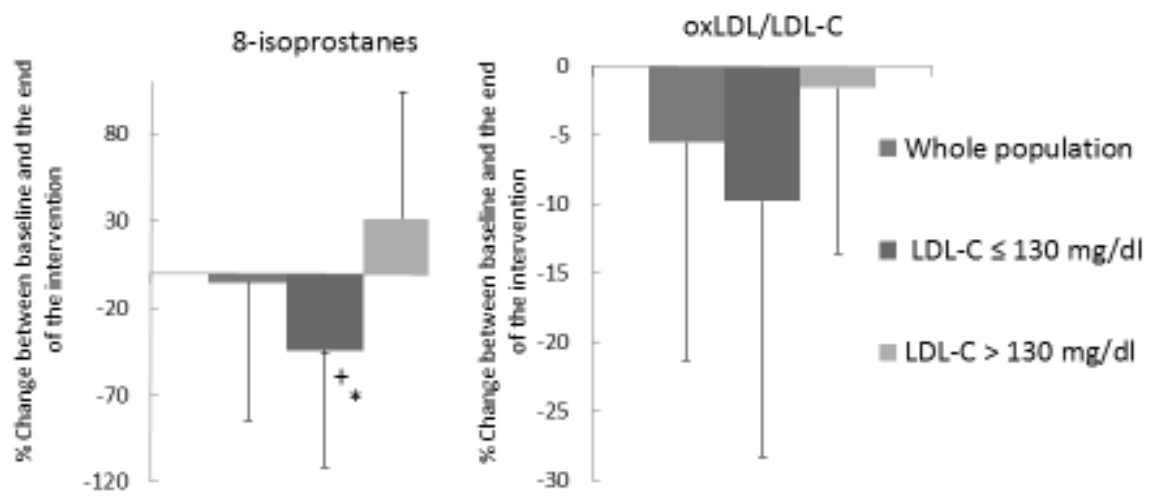

Figure 1 


\section{Highlights}

A lifestyle program improves HDL function in normocholesterolemic subjects with MetS.

Normalisation of HDL composition (CE, apoAI and TG) may account for this effect.

Such alterations in the function of HDL3c may contribute to atheroprotection in MetS.

Quality of diet impacts the functions of HDL beyond the effect of weight loss. 